\title{
How does allergic rhinitis impact the severity of COVID-19?: a case-control study
}

\author{
Ali Guvey ${ }^{1}$ (1) \\ Received: 30 March 2021 / Accepted: 19 April 2021 / Published online: 1 May 2021 \\ ○ The Author(s), under exclusive licence to Springer-Verlag GmbH Germany, part of Springer Nature 2021
}

\begin{abstract}
Background Coronavirus disease 2019 (COVID-19) is a contagious disease whose symptoms and risk factors are newly described. Some allergic diseases, including asthma, have been defined as risk factors for a poor outcome in COVID-19. We aimed to investigate the role of another allergic disease-allergic rhinitis-in the severity of COVID-19.

Methods This case-control study was conducted at Sakarya Educational and Research Hospital, Toyota Hospital and Yenikent State Hospital between March 18, 2020 and August 30, 2020. The study included a case group of 125 randomly selected patients who had been diagnosed with allergic rhinitis in advance of having COVID-19 and a control group of 125 patients without allergic rhinitis who were diagnosed with COVID-19. We evaluated all participants' statuses regarding smoking, symptoms, and hospitalization, as well as the length of their hospitalization and the number of their comorbidities. Results There were no statistically significant differences between the two groups regarding percentage of asymptomatic patients $(p=0.27)$, presence of smoking $(p=0.068)$, hospitalization status $(p=0.79)$, and hospitalization length $(p=0.55)$. From each group, two patients needed care in an intensive care unit (ICU). One patient from the case group and two from the control group died due to COVID-19.

Conclusion We found that allergic rhinitis did not affect the severity of COVID-19. However, we recommend that the literature be augmented with further studies on the COVID-19 prognosis of patients who have allergic rhinitis.
\end{abstract}

Keywords COVID-19 $\cdot$ Allergic rhinitis $\cdot$ Allergic diseases $\cdot$ Severity

\section{Background}

SARS-CoV-2, which leads to acute respiratory distress syndrome (ARDS), emerged from Wuhan City, China in December 2019 and became a rapidly spreading pandemic. The disease that results from this novel coronavirus was named coronavirus disease 2019 (COVID-19) by the World Health Organization (WHO) on February 11, 2020. The WHO declared COVID-19 a pandemic on March 11, 2020. As of December 2020, one year after the beginning of the outbreak, the total confirmed cases worldwide numbered 81 million, and there had been approximately 2 million deaths globally [1]. Diagnosis with COVID-19 is based on detection of SARS-CoV-2 via reverse transcriptase polymerase

Ali Guvey

aliguvey76@gmail.com

1 Medical Faculty, Department of Otorhinolaryngology, Kutahya Health Sciences University, Andız, Kutahya, Turkey chain reaction (RT-PCR) in the airway samples of suspected cases [2]. The most common symptoms of COVID-19 are fever, cough, fatigue, and dyspnea [3]. COVID-19 is a contagious and sometimes mortal disease whose symptoms are newly described. In contrast, allergic rhinitis is a chronic disease that is not contagious, has no potential for mortality, and whose symptoms are well described [4].

What healthcare authorities want to know while managing an outbreak includes how many people will be affected, how many of them will present to hospitals, how many will be hospitalized, how many will need intensive care unit (ICU) care, and what the mortality rate will be? It is essential to know how these variables can be affected by such factors as gender and additional morbidities.

It has been proposed that a patient's COVID-19 prognosis can be worsened by the underlying diseases that affect their immune system. So far, the known risk factors are being over 65 years old and the presence of diabetes mellitus, pulmonary disease, chronic kidney disease, hypertensive disorders, 
cardiovascular diseases, obesity, malignancy, and immune suppressive disorders [3].

The tissue alterations and inflammation inherent in allergic diseases can make allergy patients vulnerable to infections [5]. Although some studies have described poor prognoses in COVID-19 patients who are asthmatic [6], other studies on the issue have not found the same results $[7,8]$. Similar studies evaluating allergic diseases are needed, but hitherto, the largest study on this topic is a cohort survey conducted in South Korea [9], which reported that COVID19 patients who had allergic rhinitis required longer periods of hospitalization. Given the inconsistent outcomes in the literature, it has been acknowledged that more studies are required to clarify them [10].

It is known that the symptoms of allergic rhinitis can be confused with those of COVID-19. Patients who have either disease can demonstrate upper airway symptoms. Obtaining a test result that is positive for COVID-19 cannot exclude allergic rhinitis [11].

In this study, we aimed to compare the clinical course of COVID-19 in patients who have allergic rhinitis and in COVID-19 patients a control group.

\section{Methods}

The study's case group enrolled 150 participants who had been diagnosed with allergic rhinitis (coded as J30.1, J30.2, $\mathrm{J} 30.3$, or J30.4 in the International classification of diseases (ICD) 10 codes) from 2018 through 2019 and who had positive RT-PCR tests for COVID-19 at Sakarya Educational and Research Hospital, Toyota Hospital and Yenikent State Hospital between March 18, 2020 and August 30, 2020. Twenty-five patients who had allergic rhinitis accompanied by asthma were excluded from the study. The control group included patients who had positive RT-PCR tests for COVID-19 at the same hospitals and who were matched for the same gender, age interval $( \pm 5)$, and number of comorbidities as in the case group. The 144 patients in the control group were selected retrospectively from the last confirmed cases using the random numbers method among separate lists for each case that met these criteria. For two patients, the additional comorbidities did not match and 17 patients had asthma, so they excluded from the study.

The study was approved by the Sakarya University Medical Faculty's Non-interventional Studies Ethics Committee on December 12, 2020 (No. 659). This study was performed within the guidelines of the Helsinki Declaration.

The chronic diseases that are accepted as risk factors for COVID-19 by the Turkish Republic's Ministry of Health are hypertension, diabetes mellitus, chronic obstructive pulmonary disease (COPD), renal insufficiency, cancer, immunodeficiency, ischemic heart disease, and obesity. The people who received RT-PCR test results that were positive for COVID-19 and had no symptoms or mild symptoms were defined as asymptomatic or mildly symptomatic. Symptomatic was defined as having at least one of the following symptoms: fever, cough, myalgia, and arthralgia.

\section{Statistical analysis}

The sample size was calculated according to medium effect size, $80 \%$ power, and a significance level of 0.05 . The statistical analysis was conducted using SPSS version 23 (Statistical Package for Social Sciences Statistics for Windows, version 23.0, IBM Corp., Armonk, NY). The Pearson chisquare test, the Yates continuity correction chi-square test, and the Student's $t$ test were used for statistical analysis. The descriptive statistics were presented as frequency, percent, and mean \pm standard deviation. $p<0.05$ was considered statistically significant.

\section{Results}

The study was conducted using 125 allergic rhinitis patients who had contracted COVID-19 and 125 COVID-19 patients who had never been diagnosed with allergic rhinitis. In all, the data from 250 patients were evaluated. The participants' mean age was $40.6 \pm 16.1$, with the mean age of the case group being $40.6 \pm 16$ and that of the control group being $40.6 \pm 16.2$. In addition, $42.4 \%$ of participants were male, and $16.8 \%$ of the case group had symptoms of fever and/ or cough. There was no statistically significant difference between the two groups regarding the percentage of patients who were asymptomatic $(p=0.27)$. In the case group, the rate of active smokers was $19.2 \%$, and in the control group, the rate was $20.8 \%$, meaning that the groups did not differ significantly in smoking status $(p=0.068)$. In the case group, $54 \%$ of participants were hospitalized. Additionally, in the case group, the rate of hospitalized participants was 54\%, and in the control group, the rate was $70 \%$, meaning that the groups did not differ significantly in hospitalization status $(p=0.79)$. In addition, two patients from each group needed ICU care. One patient from the case group and two from the control group died due to COVID-19. Because these numbers were so small, these data were not included in the statistical analysis.

There was no statistically significant difference between the groups regarding the length of hospitalization $(p=0.55)$. In the case group, the mean hospitalization period was $7.1 \pm 4.1$ days, and in the control group, it was $7.6 \pm 3.8$ days. Table 1 compares the descriptive statistics of both groups, and Table 2 compares the lengths of hospitalization. 
Table 1 Comparison of descriptive characteristics

\begin{tabular}{llccc}
\hline Variables & & $\begin{array}{c}\text { Case group } \\
\text { Number (\%) }\end{array}$ & $\begin{array}{c}\text { Control group } \\
\text { Number (\%) }\end{array}$ & $p$ value \\
\hline Gender & Male & $53(42.4)$ & $53(42.4)$ & \\
& Female & $72(57.6)$ & $72(57.6)$ & \\
Symptom status & Symptomatic & $21(16.8)$ & $14(11.2)$ & 0.27 \\
& Asymptomatic/mildly & $104(83.2)$ & $111(88.8)$ & \\
Smoking status & symptomatic & & & \\
& Never smoked & $83(66.4)$ & $92(73.6)$ & 0.068 \\
& Former smoker & $18(14.4)$ & $7(5.6)$ & \\
Hospitalization & Current smoker & $24(19.2)$ & $26(20.8)$ & 0.79 \\
& Hospitalized & $68(54.4)$ & $70(56.0)$ & \multirow{2}{*}{0.88} \\
Number of comorbidities & Not hospitalized & $57(45.6)$ & $55(44.0)$ & \\
& No comorbidities & $106(84.8)$ & $108(86.4)$ & $15(12.0)$ \\
& One comorbidity & $16(12.8)$ & $2(1.6)$ &
\end{tabular}

Table 2 Comparison of lengths of hospitalization

\begin{tabular}{llll}
\hline Variable & $\begin{array}{l}\text { Case group } \\
\text { Mean } \pm \text { stand- } \\
\text { ard deviation }\end{array}$ & $\begin{array}{l}\text { Control group } \\
\text { Mean } \pm \text { standard } \\
\text { deviation }\end{array}$ & $*$ value \\
\hline $\begin{array}{l}\text { Length of hospitali- } \\
\text { zation }\end{array}$ & $7.1 \pm 4.1$ days & $7.6 \pm 3.8$ days & 0.55 \\
\hline
\end{tabular}

*Student's $t$ test was applied

\section{Discussion}

Although the pandemic began more than a year ago, it is still unclear why some patients' clinical course of COVID19 is serious and leads to death and why others are asymptomatic. One critical issue is why young patients who have no comorbidities may have a serious disease course that can result in death. However, there is consensus on the previously mentioned risk factors.

Several studies have investigated the status of asthma $[6,10]$ or allergic diseases $[4,9]$ in COVID-19. Approximately $80-90 \%$ of asthma patients have been determined to also have allergic rhinitis [12]. Conversely, nearly half of all allergic rhinitis patients subsequently develop asthma [13]. Despite investigations, it is not yet known how the presence of asthma and allergic rhinitis affects the course of COVID-19. It is known that the presence of allergies is a predisposing factor for viral infections in the upper airway, but it has been suggested that because the receptors that COVID-19 attaches to are less expressed in allergic patients, these patients may have a milder disease course. However, more accurate evidence about this issue has been called for $[14,15]$.
Although studies from China and the United States (US) have reported that the COVID-19 prognosis is poorer in asthmatic patients than in the non-asthmatic population, some studies have found no correlation between COVID-19 and asthma [6, 7, 16-18]. Also, no relationship has been demonstrated between allergic diseases and a severe clinical course of COVID-19. A cohort study in South Korea that included 2176 allergic rhinitis patients who tested positive for SARS-CoV-2 and 2176 control patients found a significant difference between those with allergic rhinitis and those without regarding COVID-19 prognosis. Asthmatic patients had a similar risk [9].

Our study found no significant difference between the two groups it examined regarding hospitalization status or length of hospitalization. However, another study conducted in South Korea followed 211 patients who were mildly symptomatic for COVID-19 and recorded whether they were hospitalized. Its results noted that none of the nine patients who had allergic rhinitis were hospitalized, supporting the theory that allergic rhinitis is not a risk factor for severe COVID-19 [19].

A US study that included 1526 patients concluded that having asthma did not affect COVID-19 patients' rates of hospitalization or mortality, although the prevalence of asthma was found to be higher in COVID-19 patients than in the non-asthmatic population [20]. A Turkish study of 100 COVID-19 patients did not identify asthma as a risk factor for severe COVID-19 [21].

A survey study conducted in Istanbul, Turkey, divided patients into two groups: those having atopic symptoms and those who did not. Although the atopic patients were found to have a lower frequency of severe COVID-19, the difference between the groups was not significant. The study noted that its results might have been misleading because its evaluation was based on patients' statements [22]. 
Several studies conducted early in the pandemic included no asthmatic patients among those who had severe COVID19 [23-26]. Another study found that the prevalence of severe COVID-19 was lower in asthma patients than in the local population (8). Studies from Italy did not identify asthma as risk factor for COVID-19 [27]. A Spanish study of 2226 patients did not identify asthma or allergic rhinitis as risk factors for severe COVID-19 too [28].

In the pediatric population, the clinical course of COVID19 is usually milder than in the adult and geriatric populations. However, COVID-19 can cause multisystem inflammatory syndrome, which leads to death in some children [29, 30]. The relationship of this syndrome to allergic rhinitis and other allergic diseases needs to be clarified. The results of a study of 182 children in China identified no asthmatic children who had severe COVID-19 [31]. Similarly, a US study of 291 children did not identify asthma or allergic rhinitis as risk factors for COVID-19 [32].

Limitations of our study are being retrospective nature, so the data were obtained from hospital records, not from our clinical observations.

However, being designed multicenter, the study conducted at three hospital which cover the patients from different regions of Turkey. So this situation makes the results generalizable to the country. Also, in the setting of the study, case and control groups were well randomized and matched that enabled us to avoid any bias.

\section{Conclusion}

In conclusion, our retrospective case-control study found that allergic rhinitis did not worsen the severity of COVID-19. There was no significant difference between the case and control groups regarding hospitalization status or length of hospitalization. Correspondingly, several studies in the literature have not identified allergic rhinitis or asthma as risk factors for severe COVID-19, although surveys suggesting the reverse outcome also exist. For this reason, we conclude that further studies of the COVID-19 prognosis of allergic rhinitis patients would contribute to the literature.

Supplementary Information The online version contains supplementary material available at https://doi.org/10.1007/s00405-021-06836-z.

Authors contributions The author contributed to the study conception and design. Also he performed material preparation, data collection, analysis, first draft of the manuscript, read and approved the final manuscript.

\section{Declarations}

Ethical approval The study was approved by the Sakarya University Medical Faculty's Noninterventional Studies Ethics Committee on December 12, 2020 (No. 659).

\section{References}

1. World Health Organization (29 December 2020) Weekly epidemiological update. https://www.who.int/publications/m/item/ weekly-epidemiological-update---29-december-2020. Accessed 10 January 2020.

2. Huang C, Wang Y, Li X et al (2020) Clinical features of patients infected with 2019 novel coronavirus in Wuhan. China Lancet 395(10223):497-506. https://doi.org/10.1016/S0140-6736(20) 30183-5

3. Grant MC, Geoghegan L, Arbyn M et al (2020) The prevalence of symptoms in 24,410 adults infected by the novel coronavirus (SARS-CoV-2; COVID-19): a systematic review and meta-analysis of 148 studies from 9 countries. PLoS one 15(6):e0234765. https://doi.org/10.1371/journal.pone.0234765

4. Iraj S-A, Khazaeli S (2020) COVID-19 versus allergic rhinitis. Adv Infect Dis 10:168-174. https://doi.org/10.4236/aid.2020. 103017

5. Galli SJ, Tsai M, Piliponsky AM (2008) The development of allergic inflammation. Nature 454(7203):445-454. https://doi. org/10.1038/nature07204

6. Zhu Z, Hasegawa K, Ma B, Fujiogi M, Camargo CA Jr, Liang $\mathrm{L}$ (2020) Association of asthma and its genetic predisposition with the risk of severe COVID-19. J Allergy Clin Immunol 146(2):327-329. https://doi.org/10.1016/j.jaci.2020.06.001

7. Zhang JJ, Dong X, Cao YY et al (2020) Clinical characteristics of 140 patients infected with SARS-CoV-2 in Wuhan. China Allergy 75(7):1730-1741. https://doi.org/10.1111/all.14238

8. Li X, Xu S, Yu M et al (2020) Risk factors for severity and mortality in adult COVID-19 inpatients in Wuhan. J Allergy Clin Immunol 146(1):110-118. https://doi.org/10.1016/j.jaci. 2020.04.006

9. Yang JM, Koh HY, Moon SY et al (2020) Allergic disorders and susceptibility to and severity of COVID 19: a nationwide cohort study. J Allergy Clin Immunol 146(4):790-798. https://doi.org/ 10.1016/j.jaci.2020.08.008

10. Yücel E, Tamay Z (2020) Asthma and COVID-19. J Child 20(2):76-79. https://doi.org/10.26650/jchild.2020.2.738379

11. Şeker E, Pala A, Öner Ö (2020) COVID-19 disease and its effect on the follow-up of allergic and immunologic diseases. Sakarya Med J 10(3):514-519. https://doi.org/10.31832/smj.731345

12. Leynaert B, Neukirch F, Demoly P, Bousquet J (2000) Epidemiologic evidence for asthma and rhinitis comorbidity. J Allergy Clin Immunol 106(5 Suppl):S201-S205. https://doi.org/10. 1067/mai.2000.110151

13. Corren J (1997) Allergic rhinitis and asthma: how important is the link? J Allergy Clin Immunol 99(2):S781-S786. https://doi. org/10.1016/s0091-6749(97)70127-1

14. Shukla C (2020) ACE2 expression in allergic airway disease may decrease the risk and severity of COVID-19. Eur Arch Otorhinolaryngol. https://doi.org/10.1007/s00405-020-06408-7

15. Wakabayashi M, Pawankar R, Narazaki H, Ueda T, Itabashi $T$ (2021) Coronavirus disease 2019 and asthma, allergic rhinitis: molecular mechanisms and host-environmental interactions. Curr Opin Allergy Clin Immunol 21(1):1-7. https://doi.org/10. 1097/ACI.0000000000000699

16. Bhatraju PK, Ghassemieh BJ, Nichols M et al (2020) Covid-19 in critically Ill patients in the seattle region-case series. N Engl J Med 382(21):2012-2022. https://doi.org/10.1056/NEJMoa2004 500

17. Halpin DMG, Faner R, Sibila O, Badia JR, Agusti A (2020) Do chronic respiratory diseases or their treatment affect the risk of SARS-CoV-2 infection? Lancet Respir Med 8(5):436-438. https://doi.org/10.1016/S2213-2600(20)30167-3 
18. Wu Z, McGoogan JM (2020) Characteristics of and important lessons from the coronavirus disease 2019 (COVID-19) outbreak in China: summary of a report of 72314 cases from the chinese center for disease control and prevention. JAMA 323(13):12391242. https://doi.org/10.1001/jama.2020.2648

19. Chang MC, Park YK, Kim BO, Park D (2020) Risk factors for disease progression in COVID-19 patients. BMC Infect Dis 20:445. https://doi.org/10.1186/s12879-020-05144-x

20. Chhiba KD, Patel GB, Vu THT et al (2020) Prevalence and characterization of asthma in hospitalized and nonhospitalized patients with COVID-19. J Allergy Clin Immunol 146(2):307-4. e4. https://doi.org/10.1016/j.jaci.2020.06.010

21. Günal Ö, Türe E, Bayburtlu M et al (2020) Evaluation of patients diagnosed with COVID-19 in terms of risk factors. Mikrobiyol Bul. 54(4):575-582. https://doi.org/10.5578/mb.69811

22. Naziroğlu T, Aksu K (2020) Rare atopy in COVID-19 patients or COVID-19 famine in atopic patients? Dermatol Ther. https://doi. org/10.1111/dth.14581

23. Lu X, Zhang L, Du H et al (2020) SARS-CoV-2 infection in children. N Engl J Med 382(17):1663-1715. https://doi.org/10.1056/ NEJMc2005073

24. Zheng F, Liao C, Fan QH et al (2020) Clinical characteristics of children with coronavirus disease 2019 in Hubei China. Curr Med Sci 40(2):275-280. https://doi.org/10.1007/s11596-020-2172-6

25. Zhou F, Yu T, Du R et al (2020) Clinical course and risk factors for mortality of adult inpatients with COVID-19 in Wuhan, China: a retrospective cohort study. Lancet 395(10229):1054-1062. https://doi.org/10.1016/S0140-6736(20)30566-3

26. Guan WJ, Liang WH, Zhao Y et al (2020) Comorbidity and its impact on 1590 patients with COVID-19 in China: a nationwide analysis. Eur Respir J 55(5):2000547. https://doi.org/10.1183/ 13993003.00547-2020
27. Onder G, Rezza G, Brusaferro S (2020) Case-fatality rate and characteristics of patients dying in relation to COVID-19 in Italy. JAMA 323(18):1775-1776. https://doi.org/10.1001/jama.2020. 4683

28. Borobia AM, Carcas AJ, Arnalich FM et al (2020) A cohort of patients with COVID-19 in a major teaching hospital in Europe. J Clin Med 9(6):1733. https://doi.org/10.3390/jcm9061733

29. Ziaee V, Assari R, Mamishi S et al (2020) An algorithmic approach to multisystem inflammatory syndrome in children with COVID-19: tehran children's medical center protocol. Iran J Pediatr 30(5):e108617. https://doi.org/10.5812/ijp.108617

30. Consiglio CR, Cotugno N, Sardh F et al (2020) The immunology of multisystem inflammatory syndrome in children with COVID19. Cell 183(4):968-81.e7. https://doi.org/10.1016/j.cell.2020.09. 016

31. Du H, Dong X, Zhang JJ et al (2020) Clinical characteristics of 182 pediatric COVID-19 patients with different severities and allergic status. Allergy. https://doi.org/10.1111/all.14452.10.1111/ all.14452

32. Bialek S, Gierke R, Hughes M, McNamara LA, Pilishvili T, Skoff T (2020) CDC COVID-19 response team (2020) coronavirus disease 2019 in children: United States, February 12-April 2. MMWR Morb Mortal Wkly Rep 69(14):422-426. https://doi. org/10.15585/mmwr.mm6914e4

Publisher's Note Springer Nature remains neutral with regard to jurisdictional claims in published maps and institutional affiliations. 